\title{
Cross-drug resistance to sunitinib induced by doxorubicin in endothelial cells
}

\author{
LIMIN HUANG $^{1 *}$, CHAOQUAN HU $^{2 *}$, MÉLANIE DI BENEDETTO $^{3}$, RÉMI VARIN $^{4}$, JIELIN LIU $^{2,3}$, \\ JIAN JIN ${ }^{3,5}$, LI WANG ${ }^{3}$, JEAN-PIERRE VANNIER ${ }^{4}$, ANNE JANIN ${ }^{3,6,7}$, HE LU $^{3,6}$ and HONG LI ${ }^{4}$ \\ ${ }^{1}$ Department of Oncology, People's Hospital of Guizhou Province, Guiyang, Guizhou 550000; ${ }^{2}$ Department of Surgery, \\ Affiliated Hospital of Guiyang Medical University, Guiyang, Guizhou 550004, P.R. China; \\ ${ }^{3}$ French Institute of Health and Medical Research, UMR-S 1165, University Institute of Hematology, \\ Saint Louis Hospital, Paris 75010; ${ }^{4}$ Laboratory of MERCI (EA 3829), Faculty of Medicine and Pharmacy, \\ University of Rouen, Rouen 76183, France; ${ }^{5}$ School of Medicine and Pharmaceutics, Jiangnan University, Wuxi, \\ Jiangsu 214122, P.R. China; ${ }^{6}$ Laboratory of Pathology, Paris Diderot University, Sorbonne Paris Cité, UMR-S 1165; \\ ${ }^{7}$ Saint-Louis Hospital, Laboratory of Pathology, Paris 75010, France
}

Received April 25, 2014; Accepted October 15, 2014

DOI: $10.3892 / \mathrm{ol} .2014 .2819$

\begin{abstract}
Multiple drug resistance remains an unsolved problem in cancer therapy. A previous study has demonstrated that the chemotherapeutic drug doxorubicin (Dox) induced upregulation of P-glycoprotein in endothelial cells, resulting in a 20 -fold increase in drug resistance and reduced efficiency of doxorubicin treatment in a mouse tumor model. In the present study, the cross-resistance and sensitivity of HMECd1 and HMECd2 established cell lines to anti-angiogenic drugs, particularly sunitinib, was explored. The results revealed that Dox treatment induced a significant increase in the breast cancer resistance protein (ABCG2) gene transcription and protein expression. This increase gave rise to a 4 - to 5-fold increase in the half maximal inhibitory concentration of the HMECd1 and HMECd 2 cells in response to sunitinib treatment in vitro. Functionally, the role of $\mathrm{ABCG} 2$ in the resistance
\end{abstract}

Correspondence to: $\mathrm{Dr} \mathrm{He} \mathrm{Lu}$, French Institute of Health and Medical Research, UMR-S 1165, University Institute of Hematology, Saint Louis Hospital, 1 Avenue Claude Vellefaux, Paris 75010, France E-mail: he.lu@inserm.fr

Dr Hong Li, Laboratory of MERCI (EA 3829), Faculty of Medicine and Pharmacy, University of Rouen, 22 Boulevard Gambetta, Rouen 76183, France

E-mail: 1i.lu-hong@univ-rouen.fr

*Contributed equally

Abbreviations: P-gp, P-glycoprotein; MRP1, multidrug resistance associated proteins; ABCG2, breast cancer resistance protein; qPCR, quantitative polymerase chain reaction.

Key words: drug resistance, endothelial cells, cancer therapy, ABC family, sunitinib to sunitinib was confirmed by the use of the ABCG2 inhibitors fumitremorgin $\mathrm{C}$ and diethylstilbestrol, which blocked cell resistance. The present study indicates that endothelial cells exhibit cross-resistance between cytotoxic drugs and anti-angiogenic drugs. This suggests that multiple drug resistance induced by chemotherapy in endothelial cells may affect the efficiency of anti-angiogenic drugs.

\section{Introduction}

Cancer development depends on a complex tissue environment for growth and metastasis (1). It is now widely recognized that immune reaction and vascular growth support tumor growth (2). Since that breakthrough, anti-angiogenic therapy has been successfully introduced in clinical cancer therapy to starve tumors (3-6).

Theoretically, using anti-angiogenic agents to block factors crucial to tumor angiogenesis should offer several advantages over conventional chemotherapy agents. First, anti-angiogenic therapy can treat all solid tumors without being restricted to a specific tumor type. Second, as anti-angiogenic therapy targets the endothelial cells within the tumor vasculature, the agents within the blood stream directly affect the targeted cells, without penetration of the tumor being necessary. Furthermore, anti-angiogenic drugs are not expected to give rise to drug resistance as they do not target the highly mutable cancer cell population, but rather the more genetically stable endothelial cells $(7,8)$. Anti-angiogenic therapy should thus allow for prolonged treatment with anti-angiogenic drugs, without giving rise to resistance.

Currently, hundreds of clinical trials involving anti-angiogenic agents are underway. Despite the initial promising performance of anti-angiogenic drugs in clinical trials, anti-angiogenesis therapy faces numerous challenges, including inherent and acquired resistance. The majority of cancer patients eventually demonstrate a lack of response to 
anti-angiogenic therapy while on the treatment regimen (4-6). Studies using clinical and preclinical models have documented the involvement of certain molecular and cellular mechanisms (9-11). At present, the proposed mechanisms include alternative angiogenic pathways, such as selective pressure of hypoxia, cancer stem cells, autophagy, recruitment of vascular progenitors and modulators, and tumor dormancy (11). In particular, previous studies indicate that acquired drug resistance in tumor endothelial cells is involved in drug resistance in cancer patients $(12,13)$.

Multidrug resistance is considered a major obstacle for successful chemotherapy in the treatment of cancer. Chemotherapy loses effectiveness over time. One reason is the drug resistance caused by the compensatory response of tumor cells $(10,14)$. One of the main underlying mechanisms for multidrug resistance in cancer chemotherapy is the overproduction of ATP-binding cassette (ABC) transporter, which serves as a pump to remove toxic drugs from tumor cells, thus rendering the tumor cells resistant to multiple chemotherapeutic drugs.

Clinical studies of human cancer have found a correlation between $\mathrm{P}$-glycoprotein (P-gp) overexpression in tumor tissues with decreased survival and poor prognosis (14). High P-gp expression has been found in tumor endothelial cells, likely in response to vascular endothelial growth factor stimulation (15). We have also shown that the chemotherapeutic agent doxorubicin (Dox) induces high levels of P-gp in endothelial cells (12). Our previous study established two endothelial cell lines, HMECd1 and HMECd2, that exhibited high drug resistance to doxorubicin (Dox) induction in vitro. These two stabilized sub cell lines demonstrated 15- and 24-fold increases in resistance to Dox. Acquired drug resistance in endothelial cells was also revealed to attenuate the efficacy of doxorubicin treatment in a mouse tumor model. Dox-induced drug resistance in these endothelial cells was predominantly due to MDR1/P-gp upregulation. Inhibiting the activity of $\mathrm{P}$-gp could reverse the resistance of endothelial cells. Furthermore, the drug resistance of endothelial cells attenuated the efficacy of doxorubicin treatment in vivo (12). This previous study indicated that the acquired drug resistance of tumor vessels plays a critical role in cancer therapy.

The breast cancer resistance protein (ABCG2) is another $\mathrm{ABC}$ transporter that has been identified as a molecular cause of multidrug resistance in diverse cancer cells $(16,17)$. As an efflux transporter for xenobiotics and unwanted toxic compounds, ABCG2 has been characterized as an important component of self-defense systems in organisms (18). In the brain microvasculature, ABCG2 is located on the luminal surface of microvessel endothelium and hence may constitute an important component of the blood-brain barrier (19).

Sunitinib is an oral multi-targeted receptor tyrosine kinase inhibitor of vascular endothelial growth-factor receptors $(20,21)$. Currently, sunitinib is used to treat advanced or metastatic renal cell carcinoma, gastrointestinal stromal tumors, meningioma and pancreatic neuroendocrine tumors. Clinical trials of combined sunitinib therapy with chemotherapy are ongoing (22-24). Patient resistance to sunitinib treatment has been reported $(11,25,26)$. The aim of the present study was to investigate the risk of acquired and cross-resistance to anti-angiogenic drugs in endothelial cells during chemotherapy.

\section{Materials and methods}

Materials. Mouse monoclonal anti-P-gp, anti-ABCG2 and anti-MRP1 antibodies were purchased from Abcam (Cambridge, UK). Sunitinib was obtained from Pfizer, Inc. (New York, NY, USA). Doxorubicin chlorhydrate was purchased from Amersham Pharmacia Biotech, Inc. (Uppsala, Sweden). Verapamil was obtained from Calbiochem (Billerica, MA, USA). Paclitaxel, vinblastine, cyclosporine $\mathrm{A}$, fumitremorgin $\mathrm{C}$, diethylstilbestrol and MK571 were purchased from Sigma-Aldrich (Saint Louis, MO, USA).

Cell culture. Parental and resistant HMEC-1 cell lines, obtained from Dr TL Lawley (Department of Dermatology, Atlanta, GA, USA), were cultured in MCDB-131 medium supplemented with $10 \%$ fetal calf serum (FCS), $2 \mathrm{mM}$ L-glutamine, $10 \mathrm{ng} / \mathrm{ml}$ epidermal growth factor, $1 \mu \mathrm{g} / \mathrm{ml}$ hydrocortisone, 100 units $/ \mathrm{ml}$ penicillin, and $100 \mu \mathrm{g} / \mathrm{ml}$ streptomycin, as described elsewhere $(12,27)$. Dox-resistant HMEC cells were obtained by continuously exposing cells to increasing concentrations of Dox, between 0.001 and $0.24 \mu \mathrm{g} / \mathrm{ml}$, over a 12 -week period, as previously described (12). Two sub cell lines of HMEC-1 cells were collected, HMECd1 cells were maintained in a culture with $0.08 \mu \mathrm{g} / \mathrm{ml}$ Dox and HMECd2 cells were maintained in $0.24 \mu \mathrm{g} / \mathrm{ml}$ Dox. No mutagenic agents were used to establish these Dox-resistant HMEC cells. To observe the reversibility of the drug resistance of the cells, Dox was withdrawn from the culture medium of HMECd1 and HMECd 2 cells. All cell types were digested with trypsin-EDTA once or twice a week and cultured in a $37^{\circ} \mathrm{C}$ incubator with a $100 \%$ humidified atmosphere of $5 \% \mathrm{CO}_{2}$.

MTS cell proliferation assay. Cell viability was determined using MTS cell proliferation assay (Promega, Madison, WI, USA). Cells grew to a confluence of $90 \%$ in $75 \mathrm{~cm}^{2}$ cell culture flasks and were passed into 96-well plates (7,500 cells/well). Each well contained $100 \mu \mathrm{l}$ of culture medium, which was supplemented with various concentrations of drugs or with a concentration of dimethyl sulfoxide as a control. Following incubation for either 24,48 or $72 \mathrm{~h}, 20 \mu \mathrm{l}$ of the MTS reagent was added to each well and the plate was placed in the $5 \% \mathrm{CO}_{2}$ incubator at $37^{\circ} \mathrm{C}$ for an additional $2 \mathrm{~h}$. The optical density (OD) was then read at $492 \mathrm{~nm}$ using a microplate reader (Labsystems Multiskan MS; MTX Lab Systems Inc., Vienna, VA, USA). The half maximal inhibitory concentration $\left(\mathrm{IC}_{50}\right)$ values were defined as the concentration of drug producing $50 \%$ inhibition of cell growth and the resistance index corresponding to the ratio of $\mathrm{IC}_{50}$ values between the resistant and parental cell lines. Experiments were performed in triplicate and repeated at least three times.

Blocking effect assay. The experiments used ABCG2 inhibitors, $5 \mu \mathrm{M}$ fumitremorgin $\mathrm{C}$ and $0.5 \mu \mathrm{M}$ diethylstilbestrol, and P-gp inhibitors, $2.5 \mu \mathrm{M}$ cyclosporine $\mathrm{A}, 1 \mu \mathrm{M}$ verapamil and $5 \mu \mathrm{M}$ MK571. Following incubation for 48 or $72 \mathrm{~h}$, the cell viability was assessed using an MTS assay. The reversal fold (RF) values, a measure of the potency of reversal, were obtained by fitting the data to $\mathrm{RF}=\mathrm{IC}_{50}$ of cytotoxic drug alone $/ \mathrm{IC}_{50}$ of cytotoxic drug in the presence of a modulator (28). 
Table I. Dox-induced cross-resistance to Dox and sunitinib in HMEC-1 endothelial cells.

\begin{tabular}{|c|c|c|c|c|c|}
\hline \multirow[b]{2}{*}{ Agents } & \multirow{2}{*}{$\frac{\text { HMEC-1 }}{\mathrm{IC}_{50}, \mu \mathrm{M}}$} & \multicolumn{2}{|c|}{ HMECd1 } & \multicolumn{2}{|c|}{ HMECd2 } \\
\hline & & $\mathrm{IC}_{50}, \mu \mathrm{M}$ & RI & $\mathrm{IC}_{50}, \mu \mathrm{M}$ & RI \\
\hline Sunitinib & $4.271 \pm 0.501$ & $8.585 \pm 0.642$ & $2.01^{\mathrm{a}}$ & $19.252 \pm 0.855$ & $4.51^{\mathrm{a}}$ \\
\hline Doxorubicin & $0.056 \pm 0.006$ & $0.812 \pm 0.050$ & $14.50^{\mathrm{a}}$ & $1.209 \pm 0.085$ & $21.60^{\mathrm{a}}$ \\
\hline
\end{tabular}

The cells were treated as described in the main text and tested with MTS assay. The RI was determined as the $\mathrm{IC}_{50}$ of Dox-treated $\mathrm{HMECd} 1$ or HMECd 2 cells divided by the $\mathrm{IC}_{50}$ of Dox-treated HMEC-1 cells. ${ }^{\mathrm{a}} \mathrm{P}<0.05$, vs. HMEC- 1 cells. Dox, doxorubicin; RI, resistance index; $\mathrm{IC}_{50}$, half maximal inhibitory concentration.

Evaluation of $m R N A$ expression via quantitative polymerase chain reaction $(q P C R)$. The HMEC-1, HMECd1 and HMECd2 cells were treated with $2.5 \mu \mathrm{M}$ cyclosporine A, $1 \mu \mathrm{M}$ verapamil, $5 \mu \mathrm{M}$ fumitremorgin $\mathrm{C}, 0.5 \mu \mathrm{M}$ diethylstilbestrol or $5 \mu \mathrm{M}$ MK571 for $24 \mathrm{~h}$. Subsequent to incubation, the treated and non-treated cells were harvested, and total RNA was prepared using the SV total RNA isolation system kit (Promega). The purity of total RNA was checked by a ratio of $\mathrm{A}_{260} / \mathrm{A}_{280}(>1.9)$. Total RNA (50 ng) was used to synthesize the first-strand cDNA in a $20-\mu 1$ reaction solution using the GoScript Reverse Transcription System kit (Promega). Then, $2 \mu \mathrm{l}$ of cDNA was used for qPCR in triplicates using a TaqMan ${ }^{\circledR}$ gene expression assay (Applied Biosystems, Foster City, CA, USA) and the primers for P-gp (Hs01067802_m1), ABCG2 (Hs01053790_m1), multidrug resistance protein (MRP) 1 (Hs00219905_m1), as well as the primers for TATA box binding protein (TBP) as controls (Hs99999910_m1; Applied Biosystems). qPCR was performed by $10 \mathrm{~min}$ of initial denaturation followed by 44 cycles of $15 \mathrm{sec}$ at $95^{\circ} \mathrm{C}$ and $60 \mathrm{sec}$ at $60^{\circ} \mathrm{C}$ in a BioRad CFX96® Real-time system (Bio-Rad Laboratories, Hercules, CA, USA). The $\Delta \mathrm{Ct}$ method was used to analyze the qPCR results, and TBP was used as an internal control for mRNA-level normalization.

Evaluation of protein expression using western blot analysis. Western blot analysis was performed on whole-cell lysates by incubating the cells in the lysis buffer $(10 \mathrm{mM}$ Tris $\mathrm{pH} 6.8$, $1 \mathrm{mM}$ EDTA, $10 \%$ Nonidet P-40, $1 \mathrm{mM}$ phenylmethanesulfonyl fluoride, $0.1 \% \mathrm{SDS}$ ) on ice for $30 \mathrm{~min}$. Cell debris was removed by centrifugation at $16,000 \mathrm{x}$ g for $10 \mathrm{~min}$. Protein concentration was determined by bicinchoninic acid protein assay (Thermo Fisher Scientific, Waltham, MA, USA). A $50 \mu \mathrm{g}$ protein sample from each sample was loaded on an $8 \%$ SDS-PAGE gel, and the protein was transferred to a polyvinylidene fluoride membrane using the iBlot dry blotting system (Invitrogen, Carlsbad, CA, USA). The membranes were blocked with $5 \%$ non-fat dry milk for $1 \mathrm{~h}$ and incubated with either anti-P-gp (ab-3364; 1:20; Abcam), anti-MRP1 (ab-32574; 1:250; Abcam) or anti-ABCG2 antibodies (ab-3380; 1:100; Abcam) at $4^{\circ} \mathrm{C}$ overnight. The membranes were then washed with a Tris buffered saline with Tween 20 buffer for $1 \mathrm{~h}$ and incubated with the appropriate horseradish peroxidase-conjugated secondary antibodies (Invitrogen), diluted in blocking buffer, for $1 \mathrm{~h}$ at room temperature. Subsequent to washing, western blotting luminol reagent (Santa Cruz Biotechnology, Inc., Dallas,
TX, USA) was added to the membranes and the chemiluminescence was recorded using a Fuji LAS-3000 system (Fujifilm, Tokyo, Japan). The membranes were then treated with an antibody-stripping buffer (Gene Bio-Application Ltd., Kfar Hanagid, Israel) and incubated with anti-actin antibody (1:4,000 dilution; Sigma-Aldrich) as a control.

Statistical analyses. The data were analyzed using one-way analysis of variance and Mann-Whitney U tests, as appropriate. The qPCR data is presented as the mean \pm standard error of the mean. The remaining data is presented as the mean \pm standard deviation. $\mathrm{P} \leq 0.05$ was considered to indicate a statistically significant difference.

\section{Results}

Endothelial cells resistant to anti-angiogenesis drugs. To address the question of the response of HMECd1 and HMECd2 to the anti-angiogenic drugs, the efficacy of sunitinib was tested in vitro. The first experiment with MTS assay revealed that HMEC-1 cells are initially sensitive to sunitinib treatment. However, compared with their parental cells, HMECd1 and HMECd 2 cells revealed 2.1- and 4.51-fold increases in drug-resistance to sunitinib (Table I). The increase in sunitinib resistance accompanied the increase in Dox resistance (Table I). This observation corresponded with the typical multi-drug resistance of endothelial cells in response to Dox induction.

$A B C G 2$ and P-gp are predominantly expressed in the resistant endothelial cells. qPCR was used to measure changes in drug efflux transporter gene expression in the Dox-induced resistant endothelial cells. The P-gp and ABCG2 expression in HMECd1 and HMECd 2 cells increased significantly compared to parental cells (1.41- and 1.68-fold for ABCG2; 3.4- and 7.2-fold for P-gp; Fig. 1). To evaluate the influence of the $\mathrm{ABC}$ transporter blockers used in the study of gene expression, the changes in P-gp, ABCG2 and MRP1 mRNA levels in the presence of the inhibitors of the three transporters were quantified, respectively.

There was no significant change in the gene expression of P-gp and ABCG2 in HMECd1 and HMECd2 cells when the function of P-gp or ABCG2 was blocked (Fig. 1A and B). The qPCR results also indicated that MRP1 was not induced in HMECd1 and HMECd 2 cells (data not shown). Western blotting revealed approximately two- to four-fold increases in the 
Table II. Effect of P-gp inhibitors and ABCG2 inhibitors on sunitinib resistance in HMEC-1 cells.

\begin{tabular}{|c|c|c|c|c|c|c|c|}
\hline \multirow[b]{2}{*}{ Agents } & \multirow{2}{*}{$\frac{\text { HMEC-1 }}{\mathrm{IC}_{50}, \mu \mathrm{M}}$} & \multicolumn{3}{|c|}{ HMECd1 } & \multicolumn{3}{|c|}{ HMECd2 } \\
\hline & & $\mathrm{IC}_{50}, \mu \mathrm{M}$ & RI & $\mathrm{RF}$ & $\mathrm{IC}_{50}, \mu \mathrm{M}$ & RI & $\mathrm{RF}$ \\
\hline Sunitinib & $4.271 \pm 0.501$ & $8.585 \pm 0.642$ & $2.01^{\mathrm{a}}$ & 1.00 & $19.252 \pm 0.855$ & $4.51^{\mathrm{a}}$ & 1.00 \\
\hline$+5 \mu \mathrm{M}$ fumC & $4.359 \pm 0.622$ & $5.886 \pm 0.417$ & $1.35^{\mathrm{b}}$ & 1.45 & $6.163 \pm 0.062$ & $1.41^{\mathrm{b}}$ & 3.12 \\
\hline$+0.5 \mu \mathrm{M}$ die & $4.204 \pm 0.468$ & $6.259 \pm 0.541$ & $1.48^{\mathrm{b}}$ & 1.37 & $7.159 \pm 0.057$ & $1.70^{\mathrm{b}}$ & 2.69 \\
\hline$+1 \mu \mathrm{M}$ vrp & $4.952 \pm 0.875$ & $9.159 \pm 0.356$ & 1.84 & 0.94 & $17.659 \pm 0.526$ & 3.57 & 1.09 \\
\hline$+2.5 \mu \mathrm{M}$ cysA & $4.098 \pm 0.562$ & $8.871 \pm 0.459$ & 2.16 & 0.97 & $20.348 \pm 0.328$ & 4.97 & 0.95 \\
\hline
\end{tabular}

The cells were treated as described in the main text and tested with MTS assay. The RI was determined by: $\mathrm{IC}_{50}$ of Dox-treated HMECd1 or HMECd 2 cells / $\mathrm{IC}_{50}$ of Dox-treated HMEC-1 cells. The RF was calculated by: $\mathrm{IC}_{50}$ of Dox-treated HMECd1 or HMECd2 cells / IC 50 of the same cell line treated by sunitinib + P-gp or ABCG2 inhibitors. ${ }^{a} \mathrm{P}<0.05$, vs. HMEC- 1 cells; ${ }^{\mathrm{P}} \mathrm{P}<0.05$, vs. HMECd 1 and $\mathrm{HMECd} 2$ cells without P-gp or ABCG2 inhibitors. P-gp, P-glycoprotein; ABCG2, breast cancer resistance protein; RI, resistance index; RF, resistance fold; IC 50 , half maximal inhibitory concentration; Dox, doxorubicin; fumC, fumitremorgin C; die, diethylstilbestrol; vrp, verapamil; cys A, cyclosporine A.

A

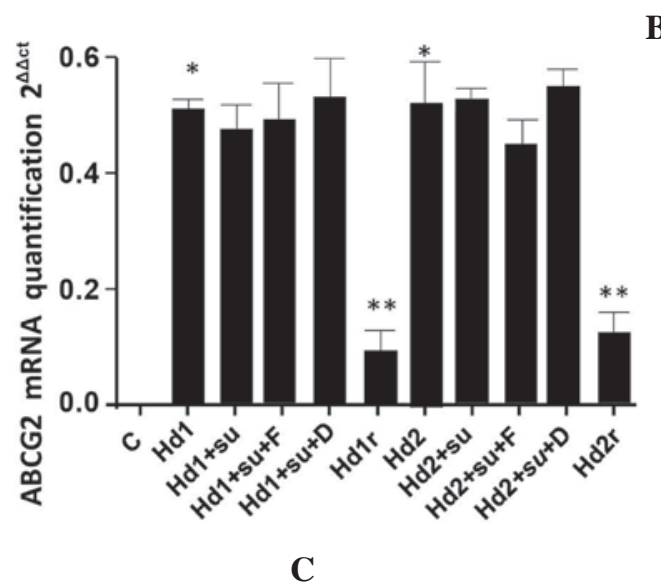

B

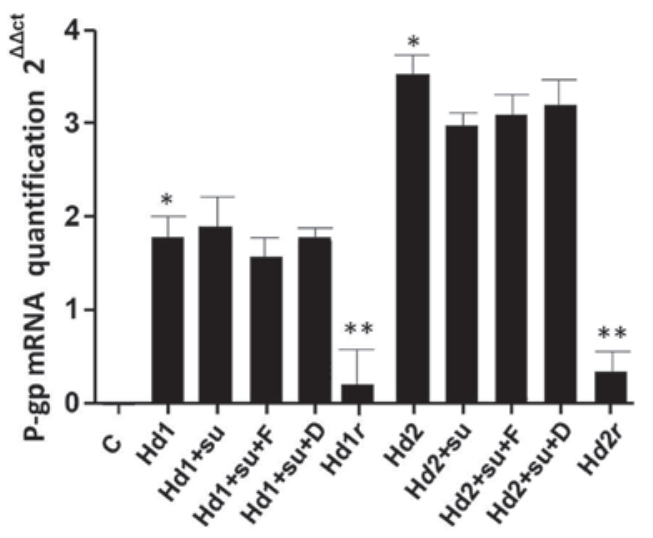

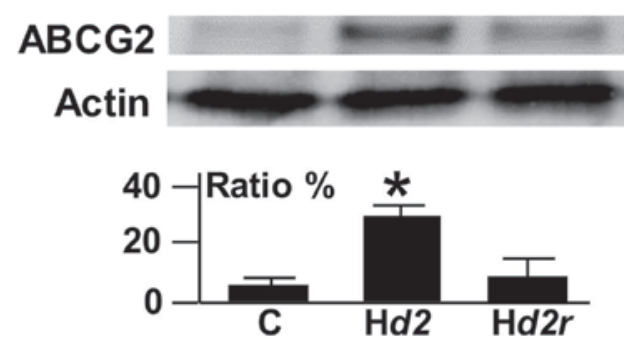

Figure 1. Induced ABCG2 expression in HMEC-1 endothelial cells. (A) qPCR (primer, Hs01053790_m1) of ABCG2 mRNA levels in treated or non-treated HMEC-1, HMECd1, HMECd2, HMECd1r and HMECd2r cells cultured without Dox for three weeks. Sunitinib, fumitremorgin C and diethylstilbestrol were used to treat the cells. The results were obtained from three independent experiments. " $\mathrm{P}<0.05$, vs. non-treated cells. (B) qPCR (primer, Hs01067802_m1) of P-gp mRNA levels in treated or non-treated HMEC-1, HMECd1, HMECd2 and HMECd2r cells. Sunitinib, fumitremorgin C, and diethylstilbestrol were used to treat the cells. The results were obtained from three independent experiments. " $\mathrm{P}<0.05$ and ${ }^{* *} \mathrm{P}<0.01$, vs. non-treated cells. (C) Western blot analysis of ABCG2 levels in HMEC-1, HMECd2 and HMECd2r cells. The data for the ratio were obtained from three repeated blots. " $\mathrm{P}<0.05$, vs. the control and Hd2r cells. C, HMEC-1; Hd1, HMECd1; Hd2, HMECd2; Hd1r, HMECd1r; Hd2r, HMECd2r; Su, sunitinib; F, fumitremorgin C; D, diethylstilbestrol; ABCG2, breast cancer resistance protein.

ABCG2 protein expression of the cells. Withdrawal of Dox in the culture media for more than three weeks resulted in a decrease in P-gp and ABCG2 expression in HMECd1 (Hd1r) and HMECd2 (Hd2r) cells (Fig. 1). This indicated that the P-gp and ABCG2 expression was reversible.

Blocking ABCG2 attenuates the resistance of Dox-induced endothelial cells to sunitinib. The survival of HMECd1 and HMECd 2 cells was examined subsequent to sunitinib treatment in the presence of the P-gp blockers cyclosporine A and verapamil, or in the presence of the ABCG2 blockers fumitremorgin $\mathrm{C}$ and diethylstilbestrol. The results revealed that only the blockade of ABCG2 function significantly restored the sensitivity of Dox-induced of endothelial cells to sunitinib (Table II). By contrast, the P-gp inhibitors demonstrated no such effect.

\section{Discussion}

Drug resistance remains a difficult, unsolved issue in cancer therapy. Since the start of the use of anti-angiogenic therapy, 
it was expected to be an exception to drug resistance $(7,8)$. However, primary or acquired drug resistance was soon reported in anti-angiogenic therapy and the mechanisms of that resistance have been periodically reviewed (9-11). In a previous study, it was demonstrated that doxorubicin successfully induced multiple resistance in endothelial cells (12). In the present study, the response of two stabilized endothelial cell lines, HMECd1 and HMECd2, to the anti-angiogenesis drug sunitinib was evaluated.

The present study provides evidence that ABCG2 mediates the substrate efflux of sunitinib in endothelial cells. The present study demonstrated that, in addition to P-gp upregulation, ABCG2 expression was upregulated in HMECd1 and HMEd 2 cells. The ABCG 2 protein levels, revealed by western blot analysis, were found to possess a two- to four-fold increase in HMECd1 and HMECd2 cells compared with their parental cells. Similarly, qPCR revealed 1.41- and 1.68-fold increases in ABCG2 gene expression in the HMECd1 and HMECd2 cells. It was revealed that P-gp was not involved in sunitinib resistance as two inhibitors of $\mathrm{P}$-gp, cyclosporine A and verapamil, failed to reverse sunitinib resistance in HMECd1 and HMEC2. By contrast, the blockade of ABCG2 activity by fumitremorgin $\mathrm{C}$ and diethylstilbestrol greatly inhibited the capacity of the cells for sunitinib resistance. These results indicate that $\mathrm{ABCG} 2$ plays a major functional role in the resistance of HMECd1 and HMEC2 endothelial cells to sunitinib in vitro. The present results were in agreement with previous reports that revealed the involvement of ABCG2 in the resistance of cells to sunitinib treatment, although the involvement of P-gp has not been excluded in in vivo studies (29-31). As resistance to sunitinib in endothelial cells can be induced by Dox, potential cross-resistance in combined therapy that uses chemotherapy and targeted therapy may occur in clinical trials.

Cross-resistance in cancer therapy was observed in clinical settings $>50$ years ago $(32,33)$. Currently, as the combined use of chemotherapy and anti-angiogenic drugs develops rapidly, it is particularly important to explore cross-resistance. Indeed, clinical trials evaluating the combined use of targeted therapy and chemotherapy are extremely dynamic. For example, $>10$ chemotherapy drugs, including cisplatin, 5-fluoroutacil and paclitaxel are currently being explored in combination with sunitinib in clinical studies (22-24). Furthermore, in the present study, resistance of the endothelial cells to other agents used in targeted therapy was observed (data not shown). Ongoing clinical trials comprise numerous anti-angiogenic drugs $(34,35)$. These trials require additional knowledge about the occurrence of cross-resistance, not only in tumor cells but also in endothelial cells.

Cross-resistance is complex as each ABC transporter can induce the efflux of a panel of chemical molecules based on physical affinity (18). Furthermore, a drug that consists of a single chemical can induce the upregulation of more than one ABC protein, as described in previous studies $(12,20)$. During the establishment and optimization of a clinical therapeutic protocol with the provided therapeutic targets, it would be beneficial to evaluate and consider the potential risk of the development of cross-resistance to the treatment drugs. From this standpoint, additional effort would aid in the optimization of the combined use of chemotherapeutic agents and anti-angiogenic agents. Notably, as cross-resistance may occur in tumor and endothelial cells, it can also be speculated that the biological properties of drug resistance in these two types of cells may exhibit differences.

Since anti-angiogenic agents have been used clinically, patient resistance to anti-angiogenic drugs has been reported and analyzed frequently. Proposed mechanisms of resistance include alternative angiogenic escape factors, an increase in the stem cell population that is resistant to hypoxia, the selection of cells with acquired metastatic and invasive potential by hypoxia and tumor cell dormancy (11). Avoiding cross-resistance is expected to contribute to the further improvement of anticancer therapy, together with strategies that target multiple pathways involved in angiogenesis and resistance.

\section{Acknowledgements}

The authors thank the Institute of Cancer (INCA, PL06_130) and the Association Ti'toine for their support and also thank Professors Soria $\mathbf{J}$ and Soria $\mathrm{C}$ for their support.

\section{References}

1. Folkman J: Tumor angiogenesis: therapeutic implications. N Engl J Med 285: 1182-1186, 1971.

2. Quail DF and Joyce JA: Microenvironmental regulation of tumor progression and metastasis. Nat Med 19: 1423-1437, 2013.

3. Ferrara $\mathrm{N}$ and Kerbel RS: Angiogenesis as a therapeutic target. Nature 438: 967-974, 2005.

4. Al-Husein B, Abdalla M, Trepte M, Deremer DL and Somanath PR: Antiangiogenic therapy for cancer: an update. Pharmacotherapy 32: 1095-1111, 2012.

5. Young RJ and Reed MW: Anti-angiogenic therapy: concept to clinic. Microcirculation 19: 115-125, 2012.

6. Wu JM and Staton CA: Anti-angiogenic drug discovery: lessons from the past and thoughts for the future. Expert Opin Drug Discov 7: 723-743, 2012.

7. Kerbel RS: Inhibition of tumor angiogenesis as a strategy to circumvent acquired resistance to anti-cancer therapeutic agents. Bioessays 13: 31-36, 1991.

8. Boehm T, Folkman J, Browder T and O'Reilly MS: Antiangiogenic therapy of experimental cancer does not induce acquired drug resistance. Nature 390: 404-407, 1997

9. Sweeney CJ, Miller KD and Sledge GW Jr: Resistance in the anti-angiogenic era: nay-saying or a word of caution? Trends Mol Med 9: 24-29, 2003.

10. Broxterman HJ, Lankelma J and Hoekman K: Resistance to cytotoxic and anti-angiogenic anticancer agents: similarities and differences. Drug Resist Updat 6: 111-127, 2003.

11. Giuliano S and Pagès G: Mechanisms of resistance to anti-angiogenesis therapies. Biochimie 95: 1110-1119, 2013.

12. Huang L, Perrault C, Coelho-Martins J, et al: Induction of acquired drug resistance in endothelial cells and its involvement in anticancer therapy. J Hematol Oncol 6: 49, 2013.

13. Hida K, Akiyama K, Ohga N, Maishi N and Hida Y: Tumour endothelial cells acquire drug resistance in a tumour microenvironment. J Biochem 153: 243-249, 2013.

14. Pakos EE and Ioannidis JP: The association of P-glycoprotein with response to chemotherapy and clinical outcome in patients with osteosarcoma. A meta-analysis. Cancer 98: 581-589, 2003.

15. Akiyama K, Ohga N,Hida Y, et al: Tumor endothelial cells acquire drug resistance by MDR1 up-regulation via VEGF signaling in tumor microenvironment. Am J Pathol 180: 1283-1293, 2012.

16. Lage $\mathrm{H}$ and Dietel M: Effect of the breast-cancer resistance protein on atypical multidrug resistance. Lancet Oncol 1: 169-175, 2000.

17. Xu J,Peng H and Zhang JT: Human multidrug transporter ABCG2, a target for sensitizing drug resistance in cancer chemotherapy. Curr Med Chem 14: 689-701, 2007.

18. Ni Z, Bikadi Z, Rosenberg MF and Mao Q: Structure and function of the human breast cancer resistance protein (BCRP/ABCG2). Curr Drug Metab 11: 603-617, 2010.

19. Cooray HC, Blackmore CG, Maskell L and Barrand MA: Localisation of breast cancer resistance protein in microvessel endothelium of human brain. Neuroreport 13: 2059-2063, 2002. 
20. Mena AC, Pulido EG and Guillén-Ponce C: Understanding the molecular-based mechanism of action of the tyrosine kinase inhibitor: sunitinib. Anticancer Drugs 21 (Suppl 1): S3-S11, 2010.

21. Shojaei F: Anti-angiogenesis therapy in cancer: current challenges and future perspectives. Cancer Lett 320: 130-137, 2012.

22. Schmitt JM, Sommers SR, Fisher W, et al: Sunitinib plus paclitaxel in patients with advanced esophageal cancer: a phase II study from the Hoosier Oncology Group. J Thorac Oncol 7: 760-763, 2012.

23. Galsky MD, Hahn NM, Powles T, et al: Gemcitabine, Cisplatin, and sunitinib for metastatic urothelial carcinoma and as preoperative therapy for muscle-invasive bladder cancer. Clin Genitourin Cancer 11: 175-181, 2013.

24. Gómez-Martín C, Salazar R, Montagut C, et al: A phase I, dose-finding study of sunitinib combined with cisplatin and 5-fluorouracil in patients with advanced gastric cancer. Invest New Drugs 31: 390-398, 2013.

25. Wang WL, Conley A, Reynoso D, Nolden L, Lazar AJ, George S and Trent JC: Mechanisms of resistance to imatinib and sunitinib in gastrointestinal stromal tumor. Cancer Chemother Pharmacol 67 (Suppl 1): S15-S24, 2011.

26. Bracci R, Maccaroni E and Cascinu S: Transient sunitinib resistance in gastrointestinal stromal tumors. N Engl J Med 368: 2042-2043, 2013.

27. Trochon-Joseph V, Martel-Renoir D, Mir LM, et al: Evidence of antiangiogenic and antimetastatic activities of the recombinant disintegrin domain of metargidin. Cancer Res 64: 2062-2069, 2004.

28. Ji BS, He L and Liu GQ: Reversal of p-glycoprotein-mediated multidrug resistance by CJX1, an amlodipine derivative, in doxorubicin-resistant human myelogenous leukemia (K562/DOX) cells. Life Sci w77: 2221-2232, 2005.
29. Kawahara H, Noguchi K, Katayama K, Mitsuhashi J and Sugimoto Y: Pharmacological interaction with sunitinib is abolished by a germ-line mutation (1291T $>$ C) of BCRP/ABCG2 gene. Cancer Sci 101: 1493-1500, 2010.

30. Mizuno T, Fukudo M, Terada T, et al: Impact of genetic variation in breast cancer resistance protein (BCRP/ABCG2) on sunitinib pharmacokinetics. Drug Metab Pharmacokinet 27: 631-639, 2012

31. Kunimatsu S, Mizuno T, Fukudo M and Katsura T: Effect of P-glycoprotein and breast cancer resistance protein inhibition on the pharmacokinetics of sunitinib in rats. Drug Metab Dispos 41: 1592-1597, 2013.

32. Hutchison DJ: Cross resistance and collateral sensitivity studies in cancer chemotherapy. Adv Cancer Res 7: 235-250, 1963.

33. Hutchison DJ: Conference on obstacles to the control of acute leukemia. Studies on cross-resistance and collateral sensitivity (1962-1964). Cancer Res 25: 1581-1595, 1965.

34. Cesca M, Bizzaro F, Zucchetti M and Giavazzi R: Tumor delivery of chemotherapy combined with inhibitors of angiogenesis and vascular targeting agents. Front Oncol 3: 259, 2013.

35. Wu XY, Ma W, Gurung K and Guo CH: Mechanisms of tumor resistance to small-molecule vascular disrupting agents: treatment and rationale of combination therapy. J Formos Med Assoc 112: 115-124, 2013. 